\title{
Narrativas urbanas de acoso sexual. Memorias, afectos y significaciones de las mujeres en la Ciudad de México
}

\author{
Edith FLORES PÉREZ \\ Departamento de Educación y Comunicación \\ Universidad Autónoma Metropolitana, Unidad Xochimilco \\ eeedithhh@gmail.com
}

Recibido: $26 / 11 / 2013$

Modificado: $01 / 05 / 2014$

Aceptado: 12/05/2014

\section{Resumen $^{1}$}

El objetivo de este trabajo es pensar la vida urbana de la Ciudad de México a través de los relatos de mujeres sobre su experiencia cotidiana en la ciudad. Para ello presentamos los resultados de una investigación cualitativa que analiza narrativas urbanas que se entretejen a partir de violencias sexuales en los espacios públicos urbanos. Exploramos las memorias, los afectos y las significaciones que narran la experiencia de las mujeres en su tránsito cotidiano por la ciudad y los relatos que sobre ella elaboran. El texto describe los principales temas y tramas que articulan el sentido de la vida urbana en contextos de violencia simbólica cotidiana para desarrollar una comprensión de la forma en que las mujeres habitan, transitan y construyen saberes e imaginarios de la ciudad a través de sus relatos.

Palabras clave: mujeres, ciudad, narrativas urbanas, violencia de género, acoso sexual.

Title: Urban Narratives of sexual harassment. Memories, feelings and meanings from women in Mexico City.

\section{Abstract}

The objective of this work is to think of urban life through narratives told by women about their daily lives in the city. In order to present the results of the research, this work analyzes different narrations referring to sexual violence directed towards women in public spaces in urban areas. This work explores the memories, affections and significance that women express in their narrations, as well as the testimonies they give about their daily experiences when traveling around the city. This text describes the main matters related to symbolic and quotidian sexual violence that women have to face in an urban context and the way they describe their experiences

${ }^{1}$ Este artículo es producto de la investigación "Género, poder y espacio urbano. Acoso y hostigamiento sexual hacia las mujeres en la Ciudad de México", realizada por Edith Flores Pérez en la Universidad Autónoma Metropolitana Unidad Xochimilco, con el financiamiento del Programa de Mejoramiento del Profesorado (PROMEP), durante el periodo 2012-2013. El equipo de investigación estuvo conformado por Emmanuel Pontones-becario PROMEP, Paola León-Servicio Social e Israel Prettel-Diseño gráfico del Archivo del Proyecto. 
FLORES PÉREZ, Edith (2014): "Narrativas urbanas de acoso sexual. Memorias, afectos y significaciones de las mujeres en la Ciudad de México" [en línea]. En: Ángulo Recto. Revista de estudios sobre la ciudad como espacio plural, vol. 6, núm. 1, pp. 57-76. En: http://www.ucm.es/info/angulo/volumen/Volumen06-1/articulos04.htm. ISSN: 1989-4015 http://dx.doi.org/10.5209/rev_ANRE.2014.v6.n1.45323

when giving their testimonies; in order to comprehend how women live and move around the city, and how they know, experience and imagine the city they depict in their stories.

Keywords: women, city, urban narratives, gender violence, sexual harassment.

\section{Índice}

1. Introducción

2. Narrar la ciudad. Horizonte teórico del estudio

3. El relato como geografía de lo subjetivo. Aproximación metodológica

4. Narrativas urbanas de acoso sexual

4.1. Ciudad hostil. Miedo y violencias sexuales cotidianas

4.2. Ciudad de paso. Memorias, afectos y resonancias del acoso sexual

4.3. Andar la ciudad. Procesos de agencia y creatividad femenina

5. Coda

\section{Introducción}

El objetivo de este trabajo es pensar la vida urbana de la Ciudad de México en el contexto social actual, a través de los relatos de mujeres que narran su experiencia cotidiana en la ciudad. Para ello presentamos los resultados de una investigación cualitativa que analiza un corpus de narrativas que se entretejen a partir de violencias sexuales dirigidas principalmente a las mujeres en el espacio urbano.

La relevancia de este análisis es pensar la ciudad desde una visión comprensiva y crítica en un contexto social donde, en la última década, se han hecho importantes cambios en materia de legislació ${ }^{2}$ para regular la violencia de género que afecta de manera profunda a la sociedad mexicana $y$, en particular, a las mujeres y las niñas. Si bien la puesta en marcha de leyes y normas constituye un avance importante, lo que presenciamos es un desfase entre los cambios en la ley y los patrones de dominación masculina que organizan las prácticas y las relaciones sociales cotidianas, resultado de un proceso histórico de construcción social de condiciones de desigualdad y jerarquías entre hombres y mujeres, que Bourdieu (2000) ha descrito como el producto de un trabajo continuado de reproducción y naturalización de la violencia al que contribuyen agentes singulares y sociales e instituciones como la Familia, la Iglesia, la Escuela, el Estado. De ahí la importancia de visibilizar las condiciones de desigualdad y construir marcos de comprensión que correspondan a la complejidad de los procesos sociales y subjetivos que generan la

\footnotetext{
${ }^{2}$ Ley General de Igualdad entre Hombres y Mujeres (2006), Ley General de Acceso de las Mujeres a una Vida Libre de Violencia (2007), Ley para Prevenir y Sancionar la Trata de Personas (2007), Ley que despenaliza el aborto hasta la décima segunda semana de gestación (2007).
} 
violencia y la reproducen en múltiples niveles, desde la discriminación, el acoso y el hostigamiento, el abuso y la violación, la trata, la explotación y el feminicidio -como su expresión más radical.

Nuestro trabajo se centra en el caso de las violencias sexuales dirigidas a las mujeres en el espacio urbano en el marco de micro interacciones entre desconocidos. Nos centramos en este fenómeno con la intención de analizar la dimensión espacial de las violencias que se ejercen de manera física y simbólica sobre los cuerpos mediante mecanismos de carácter anónimo, de duración efímera y aparentemente evanescente (Gaytán 2009), considerados como inofensivos por su "intangibilidad". Nos ocupamos de la experiencia de las mujeres para conocer, a través de sus relatos, las memorias, afectos y significaciones que articulan la experiencia femenina en la ciudad. En el texto se describen las principales dimensiones temáticas que configuran el sentido de la vida urbana para las mujeres en contextos sociales donde la violencia de género se ha instalado en la cotidianidad, con el propósito de comprender la forma en que las mujeres habitan, transitan y construyen saberes e imaginarios de la ciudad a través de sus relatos.

\section{Narrar la ciudad. Horizonte teórico del estudio}

Teniendo como horizonte de pensamiento las geografías de género, tomamos como punto de partida la crítica de Sabaté, Rodríguez y Díaz (2010), en torno a la noción de espacio que lo ha considerado neutro, asexuado y homogéneo. Las autoras subrayan la necesidad de incorporar el género como categoría de análisis para problematizar los usos y experiencias del espacio, diferenciales y jerárquicos entre hombres y mujeres, y en este sentido, develar los mecanismos sociales y culturales que sostienen la subordinación de las mujeres, visibilizando las formas en que las relaciones de dominación organizan los espacios urbanos. La comprensión que brinda el enfoque de género para el estudio del espacio construido socialmente es tan importante como el análisis de los procesos históricos, económicos, culturales, que lo producen a distintas escalas.

En este orden de ideas, la temporalidad y espacialidad de la vida cotidiana son nociones fundamentales para el estudio del género y la ciudad. De acuerdo con Sabaté et al. (2010), las imágenes subjetivas y el conocimiento del espacio emergen de las áreas de la actividad cotidiana que supone tiempos y espacios demarcados material y simbólicamente -los lugares visitados, los trayectos realizados. El espacio cotidiano y los paisajes urbanos están constituidos así por un conjunto de lugares, trayectos y superficies como la vivienda, el lugar de trabajo, la escuela, las casas de amigos y familiares-, sobre los que se construyen determinadas valoraciones que tienen un significado simbólico para quienes lo han moldeado y habitado. 
Desde este punto de vista, las vivencias, las percepciones y representaciones construidas socialmente son tan importantes como el espacio físico en la configuración de las relaciones, afectos y simbolismos que se establecen entre el sujeto individual o colectivo y su entorno. En este mismo sentido, Soto (2011) también ha señalado que la experiencia de la ciudad está intrínsecamente vinculada no sólo con su dimensión material, sino con las emociones, sentimientos, deseos y miedos que configuran la experiencia espacial individual y colectiva. De este modo, la autora afirma que el espacio vivido, la superposición de percepciones y la posibilidad de simbolizar están ligados a procesos emocionales que transforman el espacio dándole sentido y significados.

Tal construcción de experiencias y significados se sustenta en un orden de poder -en función del género, la clase, el grupo etario, la etnia, la actividad realizada- que produce una serie de matices y gradaciones respecto a cómo se construyen socialmente los espacios y cómo las personas y los grupos ocupan un lugar simbólica y materialmente en ellos. La idea central es que la división social del espacio-tiempo cotidiano organizado por una serie de normativas de género, además de regular, controlar y delimitar el acceso a lugares, genera una forma de estar en ellos y una diferente posición en la sociedad que a su vez conlleva una experiencia diferencial del mundo que nos rodea (Del Valle 1997).

Para abordar el acoso sexual en estas coordenadas, desde el punto de vista de la psicosociología urbana, la noción de "micro interacciones entre extraños" permite construir un marco de inteligibilidad en nuestro trabajo. Esta noción, ha sido referida por Aguilar (2013) en torno al estudio de los espacios públicos a partir de determinadas interacciones sociales entre extraños como micro situaciones que se han naturalizado fundamentalmente por su carácter efímero y fugaz, formando parte de las temáticas de la ciudad regularmente desapercibidas como objetos de análisis social.

Una veta interesante de análisis dentro de este contexto de estudios, sobre el espacio público, bien puede estar representada por un esfuerzo en captar algunas pautas de su uso desde la perspectiva de las micro interacciones que en él se realizan. Ello supone asumir el valor de los actos cotidianos, en apariencia intrascendentes, para captar una de las dimensiones siempre presentes en la vida urbana constituida por el contacto interpersonal entre extraños. (Aguilar 2013: 89)

Si bien coincidimos con estas observaciones, consideramos que dentro de las múltiples interacciones y relaciones sociales enmarcadas como micro interacciones, la opacidad que acompaña el caso de las escenas de acoso sexual como objeto de estudio no sólo 
obedece al carácter efímero y fugaz de su acontecer, sino a una visión predominante de la violencia física sobre la simbólica, es decir, de los mecanismos palpables de la dominación que conllevan "pruebas" tangibles sobre aquellas expresiones que operan de manera soterrada y encubierta. En un estudio sociológico sobre acoso sexual realizado por Gaytán, la autora hacía esta advertencia, al señalar que la principal implicación que se desprende de las características del medio para los significados que adquiere el acoso sexual en los lugares públicos es la "aparente evanescencia de las interacciones de acoso, que ocurren en breves momentos de un trasbordo o un viaje, sin dejar huellas palpables de su ocurrencia" (Gaytán 2009: 236). Al referirnos a la violencia simbólica, atendemos a lo que Bourdieu describió en términos de una "violencia amortiguada, insensible, e invisible para sus propias víctimas, que se ejerce esencialmente a través de los caminos puramente simbólicos de la comunicación y el conocimiento o, más exactamente, del desconocimiento, del reconocimiento 0 , en último término, del sentimiento" (Bourdieu 2000: 12).

Bajo este enfoque enfatizamos el reconocimiento de la perspectiva del sujeto que habita el lugar, su experiencia en el espacio y los significados que construye sobre él -ya sea que lo habite de manera circunstancial o de forma prolongada-, para conocer y analizar la producción social del espacio urbano a partir de las múltiples formas de narrar la ciudad, como formas de experimentarla, de habitarla, transitarla y sentirse en ella cotidianamente.

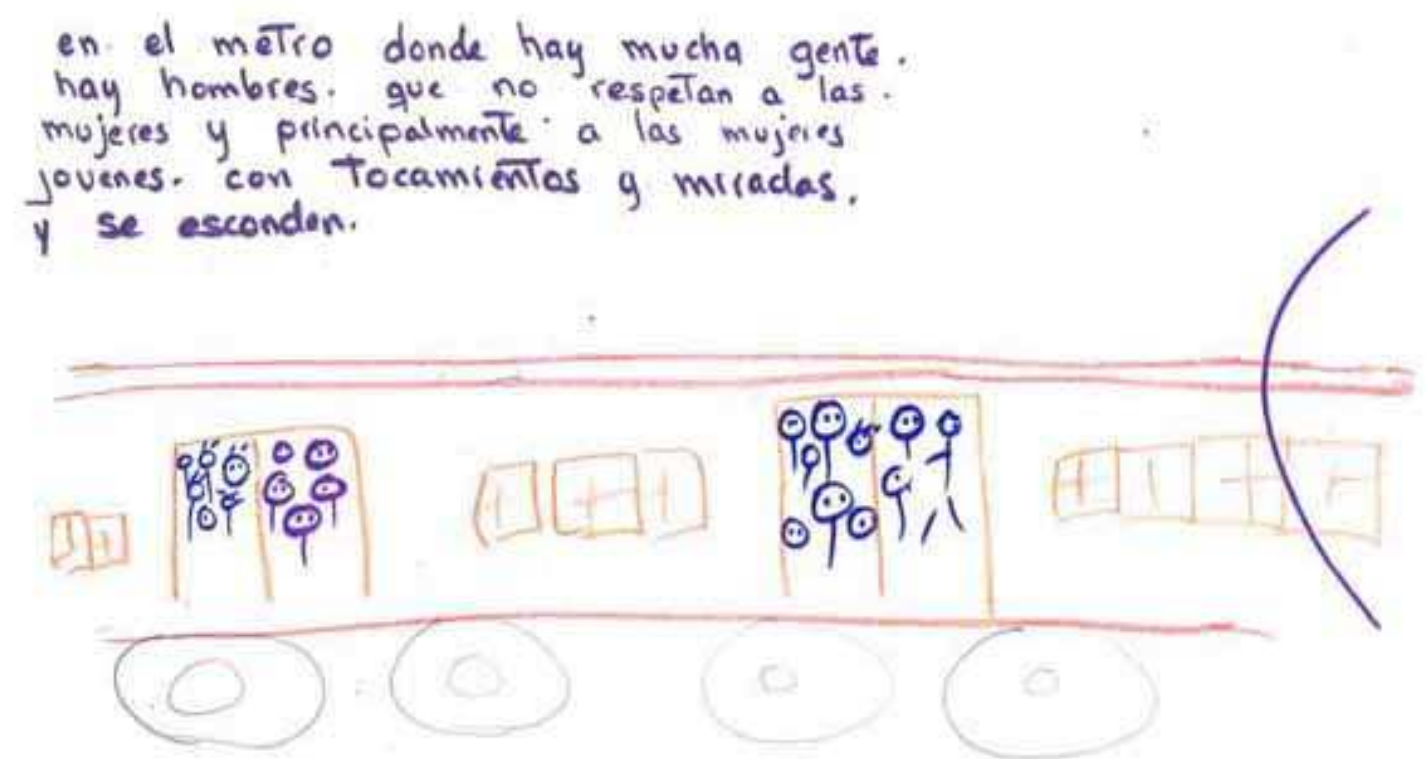

Figura 1. Guillermina, 48 años, casada, 2 hijos, enfermera. 
FLORES PÉREZ, Edith (2014): "Narrativas urbanas de acoso sexual. Memorias, afectos y significaciones de las mujeres en la Ciudad de México" [en línea]. En: Ángulo Recto. Revista de estudios sobre la ciudad como espacio plural, vol. 6, núm. 1, pp. 57-76. http://www.ucm.es/info/angulo/volumen/Volumen06-1/articulos04.htm. ISSN: 1989-4015 http://dx.doi.org/10.5209/rev_ANRE.2014.v6.n1.45323

\section{El relato como geografía de lo subjetivo. Aproximación metodológica}

En el marco de las Geografías constructivistas, fenomenológicas y experienciales, Lindón (2008), ha planteado la articulación entre la materialidad del espacio y el sentido que los sujetos producen sobre él, como una vía de aproximación teórico-metodológica que posibilita el estudio y comprensión de la construcción social del espacio desde la interpretación de la experiencia o vivencia del sujeto, de la mano de las acciones y las prácticas que lleva a cabo. A través del relato el sujeto da cuenta de su experiencia espacial, que elabora con relación a los lugares, las prácticas y las acciones que ahí acontecen y los sujetos que las realizan. En su forma y contenido el relato permite el acceso a la subjetividad, de hecho la produce: entretejiendo los núcleos de significado de las prácticas espaciales y el sentido que tienen para el sujeto. Dentro de las formas de discursividad, Lindón propone las "narrativas de vida espaciales" como versiones interpretadas de lo vivido, que describe del siguiente modo:

Un relato organizado y secuencializado espacio-temporalmente de experiencias vividas por el sujeto en ciertos lugares. Es un relato en el cual el lugar -con toda su singularidad- se hace parte de la experiencia allí vivida, influye de alguna forma en la experiencia, le imprime una marca. Otras veces las narrativas de vida espaciales corresponden a experiencias vividas por el narrador en un conjunto de lugares que van articulándose entre sí por las experiencias mismas o por la biografía del narrador. Esto suele suceder con el caso de las narrativas sobre movilidad espacial, 0 sobre trayectorias de desplazamientos, en donde es la vida del narrador la que conecta los lugares que de otra forma podrían no tener vínculos, o los tendrían de otro tipo. (Lindón 2008: 19)

La concepción del espacio construido socialmente como espacio vivido y experimentado conlleva implicaciones metodológicas que, de acuerdo con Lindón (2008), deben sustentarse en la producción de información basada en la perspectiva del sujeto. Siguiendo esta línea de pensamiento, Aguilar (2009) sostiene que la perspectiva narrativa es una vía privilegiada en la investigación social para el análisis de la vida urbana, en tanto produce historias que contar como formas de habitar la ciudad.

En los relatos urbanos que se cuentan toman forma los conflictos, las relaciones, los afectos y sentidos que los sujetos construyen alrededor de su espacialidad cotidiana. Si bien se identifican ciertas narrativas establecidas sobre la vida urbana que construyen una imagen de la ciudad reconocida, coexisten otras narrativas que contrastan con las nociones consolidadas de desarrollo y oportunidad de las ciudades, dando paso a experiencias narradas desde la alteridad étnica, de grupos etarios y de género. 
FLORES PÉREZ, Edith (2014): "Narrativas urbanas de acoso sexual. Memorias, afectos y significaciones de las mujeres en la Ciudad de México" [en línea]. En: Ángulo Recto. Revista de estudios sobre la ciudad como espacio plural, vol. 6, núm. 1, pp. 57-76. En: http://www.ucm.es/info/angulo/volumen/Volumen06-1/articulos04.htm. ISSN: 1989-4015 http://dx.doi.org/10.5209/rev_ANRE.2014.v6.n1.45323

Es en las voces de los ciudadanos que es posible encontrar recreaciones de lo local y la vida cotidiana que no están articuladas a estas grandes narrativas de lo urbano y permiten conocer modalidades novedosas en cuanto al vínculo con lo urbano desde la escala de la experiencia del habitante. (Aguilar 2009: 160)

Con base en estos referentes teórico-metodológicos, diseñamos una investigación cualitativa para producir narrativas urbanas basadas en experiencias de acoso sexual dirigidas hacia las mujeres en su tránsito cotidiano por la ciudad. El análisis se centra no en el acto violento como hecho aislado, ni en el perfil y las motivaciones del perpetrador, sino en las dimensiones temáticas que interactúan entre sí configurando la experiencia urbana de las mujeres tanto desde la singularidad de la experiencia como del contexto social que la produce.

Para la producción de narrativas de vida espaciales (Lindón 2008), llevamos a cabo 12 entrevistas en profundidad y 6 entrevistas grupales bajo una adaptación de la técnica de los grupos de discusión ${ }^{3}$ (Scribano 2008), con mujeres que usaban el transporte público de manera cotidiana y eran habitantes de colonias populares de la Zona Metropolitana del Valle de México (ZMVM) ${ }^{4}$. Como parte de las estrategias metodológicas, al finalizar las entrevistas grupales solicitamos realizar un dibujo o composición visual ${ }^{5}$ a cada una de las mujeres para representar escenas urbanas de acoso sexual. En este artículo presentamos algunas de las composiciones que elaboraron las participantes del estudio (figuras $1,2,3,4$ y 5 ).

Debido a que el trabajo realizado con el material gráfico obtenido es objeto de otro artículo ${ }^{6}$, sólo mencionaremos que con base en los dibujos y bricolajes -un total de 52- elaboramos Escrito

\footnotetext{
${ }^{3}$ Las entrevistas grupales se conformaron por 6 a 8 participantes según la edad, el nivel educativo, la condición social y la zona donde vivían. Tanto las entrevistas en profundidad como las grupales fueron organizadas por el rango de edad de las participantes, es decir, 2 entrevistas grupales y 4 individuales con mujeres de 18 a 29 años, de 30 a 39 y de 40 años y más.

${ }^{4}$ La Zona Metropolitana del Valle de México está integrada por el Distrito Federal, 59 municipios del Estado de México y un municipio del estado de Hidalgo. Fuente: http://www.inegi.org.mx/est/contenidos/espanol/sistemas/CEZM12/estatal/default. htm.

5 En cada entrevista grupal se solicitó a las participantes realizar un dibujo o composición visual de manera individual para representar una escena de acoso sexual en la ciudad. Se proporcionaron materiales diversos (cartulinas, plumones, crayones, revistas, tijeras, pegamento) y una vez que terminaron su dibujo o bricolaje, cada participante presentó la suya frente al grupo, cerrando la entrevista con esta actividad.

${ }^{6}$ Para una descripción detallada del trabajo realizado con el material gráfico, vid. Flores (2013).
} 
FLORES PÉREZ, Edith (2014): "Narrativas urbanas de acoso sexual. Memorias, afectos y significaciones de las mujeres en la Ciudad de México" [en línea]. En: Ángulo Recto. Revista de estudios sobre la ciudad como espacio plural, vol. 6, núm. 1, pp. 57-76. En: http://www.ucm.es/info/angulo/volumen/Volumen06-1/articulos04.htm. ISSN: 1989-4015 http://dx.doi.org/10.5209/rev_ANRE.2014.v6.n1.45323

en la banqueta. Archivo de memoria visual ${ }^{7}$ con el objetivo de documentar y visibilizar las escenas de acoso sexual narradas por mujeres desde su experiencia urbana, con la intención de mostrar a través de las representaciones de las mujeres, qué es y cómo se vive el acoso sexual y concienciar sobre este problema social.

Por su parte, en este escrito nos centramos en el estudio de las narrativas espaciales de acoso sexual y la experiencia subjetiva de las relaciones de dominación en el espacio urbano, con el propósito de comprender y analizar las implicaciones de la violencia de género en las formas de habitar la ciudad y de construir el espacio a través de los relatos que sobre él elaboran las mujeres.

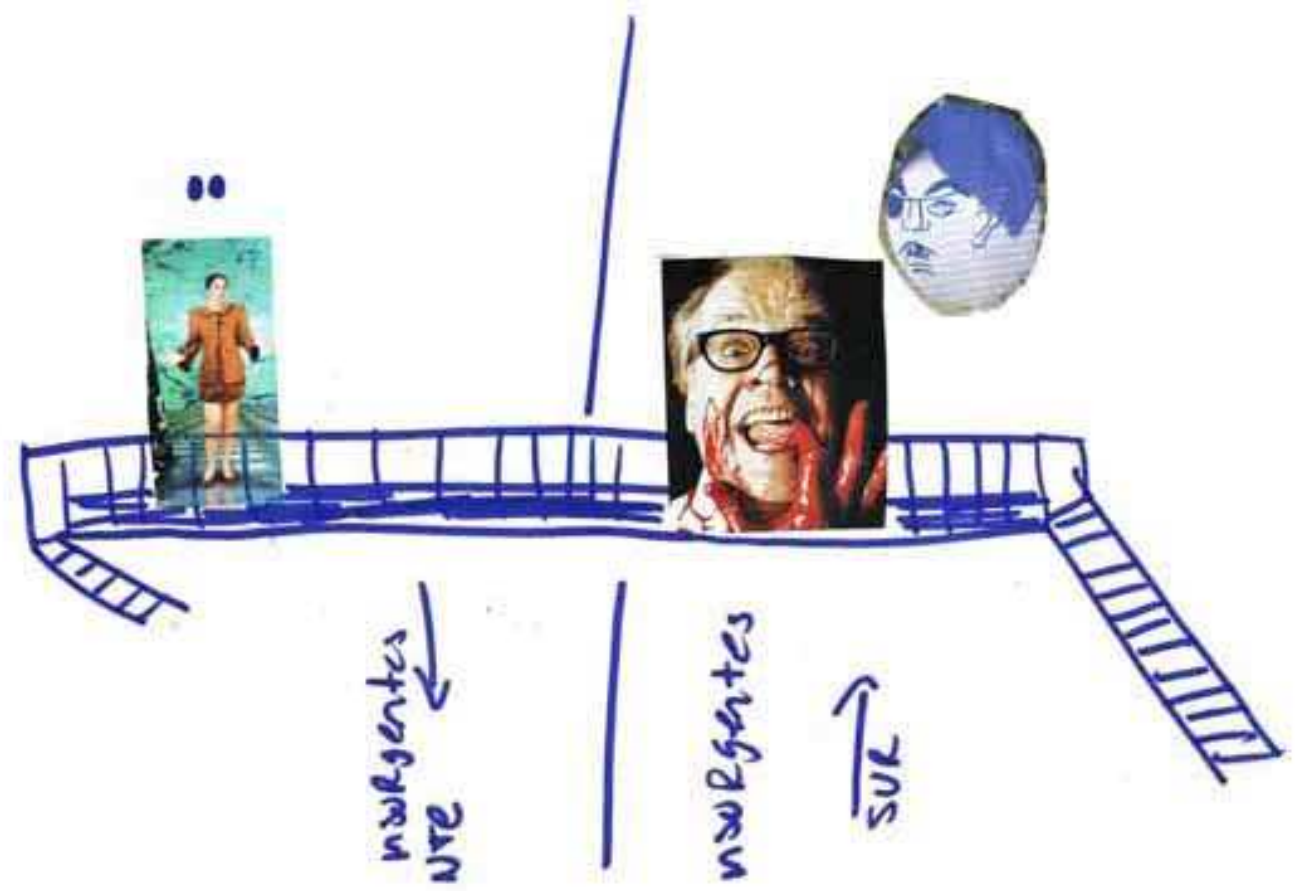

Figura 2. Katia, 34 años, casada, sin hijos, empleada.

\section{Narrativas urbanas de acoso sexual}

En los relatos de las mujeres, la ciudad emergió polarizada en sus representaciones y vivencias: se admira tanto como se teme. De la ciudad se aprecia la belleza de sus plazas, edificios y jardines, y se valora la amplia gama de posibilidades culturales, de recreación y de ocio que ofrece. Al mismo tiempo, la ciudad es recreada como una

7 Escrito en la banqueta. Archivo de memoria visual se construyó a partir de tres formatos de presentación que elaboramos con los dibujos y bricolajes: 1) La compilación de los dibujos y bricolajes en un disco compacto que fue entregado al mayor número posible de participantes del estudio una vez que la investigación se dio por concluida, 2) Una selección de 30 imágenes impresas en formato cartel $(80 \mathrm{~cm} \times 60 \mathrm{~cm})$ con las cuales se montó una exposición itinerante y 3) Un relato audiovisual producido a partir de los audios de las entrevistas y el material gráfico. 
FLORES PÉREZ, Edith (2014): "Narrativas urbanas de acoso sexual. Memorias, afectos y significaciones de las mujeres en la Ciudad de México" [en línea]. En: Ángulo Recto. Revista de estudios sobre la ciudad como espacio plural, vol. 6, núm. 1, pp. 57-76. http://www.ucm.es/info/angulo/volumen/Volumen06-1/articulos04.htm. ISSN: 1989-4015 http://dx.doi.org/10.5209/rev_ANRE.2014.v6.n1.45323

fuente de temores, problemas y ansiedades relacionadas con el desempleo, la economía, la vivienda, la movilidad, el caos vial, la insuficiencia de servicios, la inseguridad, la delincuencia, el secuestro exprés, la agresión de la gente y la violencia sexual, particularmente dirigida a las mujeres.

A partir de explorar la vida de las mujeres en la ciudad, se desplegó un campo discursivo de la violencia sexual como experiencia socialmente compartida, cotidiana y prefigurada que condiciona las prácticas espaciales y las valoraciones subjetivas de la ciudad. A continuación describimos las principales dimensiones temáticas de los relatos urbanos entretejidos por experiencias de violencias sexuales que las mujeres han vivido en sus desplazamientos y recorridos cotidianos.

\subsection{Ciudad hostil. Miedo y violencias sexuales cotidianas}

El miedo a la violencia sexual es construido en términos de un saber anticipado y socialmente compartido acerca de la ciudad. Esto significa que estar o desplazarse por sus calles y avenidas, a pie o en el transporte colectivo, implica para las mujeres un riesgo de ser objeto de agresiones sexuales mayor que para otros grupos (gays, lesbianas, transexuales, travestis, hombres heterosexuales, por ejemplo). El imaginario urbano del miedo como construcción social y cultural, organiza las relaciones entre los géneros, las prácticas espaciales y los relatos urbanos en función de la representación del agresor como un sujeto masculino y de la víctima como un sujeto femenino.

En las narrativas de las mujeres, la ciudad emerge como fuente de peligro a través de la localización física de ciertas zonas consideradas de mayor riesgo, sin embargo, las participantes consideran que la violencia sexual no necesariamente tiene una ubicación espacial fija y delimitada, su descripción es más cercana a una atmósfera de inseguridad que traspasa fronteras y reviste con su omnipresencia la ciudad. Si bien esto no significa que cada mujer viva un episodio de violencia sexual cada vez que se encuentra en el espacio público, las participantes señalan que, de manera cotidiana, le sucede a una mujer o a otra. Asimismo especifican que el acoso sexual es una experiencia aleatoria y latente, que produce una atmósfera hostil principalmente para las mujeres.

Participante: Igual y a una sola mujer no le pasa todos los días, no, pero si vas a la escuela, iah! a la chava del otro salón le pasó y a la de acá también, o a mi amiga y a mí también nos pasó, no sé, yo creo que sí es algo de todos los días a todas horas en todas partes...

Participante: No, yo creo que... puede ser en la calle también...

Participante: puede ser que te grite y pasen y te den una nalgada $o$ algo así, puedes ir en el camión y uno ya se te arrimó, o el otro ya se 
FLORES PÉREZ, Edith (2014): "Narrativas urbanas de acoso sexual. Memorias, afectos y significaciones de las mujeres en la Ciudad de México" [en línea]. En: Ángulo Recto. Revista de estudios sobre la ciudad como espacio plural, vol. 6, núm. 1, pp. 57-76. En: http://www.ucm.es/info/angulo/volumen/Volumen06-1/articulos04.htm. ISSN: 1989-4015 http://dx.doi.org/10.5209/rev_ANRE.2014.v6.n1.45323

te sentó a lado y te está diciendo cosas en el oído, puedes estar en la escuela y que igual, chavos te griten cosas o te hagan cosas, yo creo que no hay un lugar como específico... (Grupo 2: 18-29 años)

Entonces en ese corto recorrido... [de casa al trabajo] me han llegado a decir de todo, desde esos comentarios que te levantan el ánimo que dice uno, ah bueno sí, hasta bueno pero ¿qué parezco? o ¿por qué? ¿por qué me ofenden o por qué me tratan así? De todo y en tres cuadras, y aquí digamos que es aquí en Villa Coapa, no es así como digamos que no está tan saturado de gente como en el sitio del Centro o así, y sí, como dice ella, a veces dice uno, iay, me voy con esta blusita! pero no, porque ¿quién sabe qué me vayan a decir o qué me vayan a hacer? Entonces ya se priva uno de sentir cosas o de sentirse a gusto... porque cuando ya sale uno de su casa, ya está expuesto a un ambiente que puede ser hostil para las mujeres... (Participante Grupo 1: 18-29 años)

De acuerdo con las cavilaciones de las mujeres, las violencias sexuales en los espacios públicos son aleatorias porque cualquier mujer está expuesta independientemente de su edad, de sus características físicas y de su condición social. Asimismo, son violencias latentes porque salir a la calle implica el riesgo de ser agredidas sexualmente a cualquier hora del día y en cualquier lugar, por el hecho de ser mujer.

No es cuestión ni de como estés, ni de la edad que tengas, ni tampoco de que te subas o no al transporte, porque te pasa en la calle, te pasa en la escuela, o sea, en todos lados. (Participante Grupo etario: 40 años y más)

Para las mujeres el miedo se activa con mayor intensidad en determinadas circunstancias tales como lugares con luz escasa, solitarios y particularmente en la noche. Sin embargo, en sus relatos se refieren a un temor generalizado que no necesariamente tiene un referente empírico, su soporte es la representación y el imaginario de una ciudad hostil donde el miedo y la sensación de amenaza están presentes en su vida cotidiana.

Yo también he conocido historias de mujeres que van caminando, desde que va uno en bicicleta o van en su coche, y de que les meten la mano, que van y les meten la mano a las chavas, o sea, yo creo que hasta donde menos te lo imagines, te quieren tortear o el chiste es tocarte o gritarte. (Participante Grupo 1: 18-29 años)

Una de las escenas que mayor temor produce en las mujeres es la posibilidad de ser violentadas cuando éstas se encuentran solas. Esto se sostiene en la idea de que la magnitud de la agresión puede aumentar si el agresor se percata de esta condición, y pasar, por 
FLORES PÉREZ, Edith (2014): "Narrativas urbanas de acoso sexual. Memorias, afectos y significaciones de las mujeres en la Ciudad de México" [en línea]. En: Ángulo Recto. Revista de estudios sobre la ciudad como espacio plural, vol. 6, núm. 1, pp. 57-76. En: http://www.ucm.es/info/angulo/volumen/Volumen06-1/articulos04.htm. ISSN: 1989-4015 http://dx.doi.org/10.5209/rev_ANRE.2014.v6.n1.45323

ejemplo, de las miradas lascivas o las frases ofensivas al contacto físico, a la persecución y desembocar en la violación. La ilación de una cadena de acontecimientos basados en el imaginario del miedo a la violencia sexual se articula con la percepción de un sentimiento de mayor vulnerabilidad e indefensión ante el sujeto y la escena de la agresión.

Durante las entrevistas, las narraciones de las mujeres desencadenaban los recuerdos de otras, lo que permitió recuperar un conjunto de eventos individuales que conforman una historia colectiva de violencias sexuales dirigidas a las mujeres en los espacios públicos urbanos. Lejos de recopilar o hacer una sumatoria de acontecimientos, la experiencia del acoso sexual emergió en los discursos como una escena urbana cotidiana socialmente compartida, esto es, como uno de los episodios más comunes del repertorio de vivencias de las mujeres en la ciudad. En sus discursos identificamos la voz de un "nosotras" que asume la agresión cuando agreden a una.

De este modo, las prácticas espaciales referidas por todas las participantes del estudio, cuando menos una vez en su vida han sido signadas por alguna experiencia de violencia sexual en la calle o en el transporte público. En los relatos de su vida en la ciudad, las mujeres evocaron "ofensas", "agresiones sexuales", "faltas de respeto", "vulgaridades", "burlas", "miradas lascivas", "groserías", "cochinadas", "acciones desagradables", "amenazas", "atentados contra su persona", "persecuciones", "sustos", "atropellos", "invasiones" sobre sus cuerpos, realizados por uno o varios sujetos desconocidos que mayoritariamente identificaron como un sujeto masculino. Estas interacciones son descritas como experiencias disruptivas que han vivido de manera intimidante y denigrante, llevando consigo el monto de la agresión, pues la mayoría de las veces, las mujeres las viven en silencio y se sobreponen a ellas a partir de sus propios recursos y estrategias personales.

En la lectura de las mujeres estas acciones se llevan a cabo con la intención de causar daño, burla o crueldad, y quien las comete es plenamente consciente de ello. La conciencia de la acción y su intencionalidad hace del acto violento una escena aún más ofensiva según así lo han relatado.

Yo iba sentada donde va un solo lugar, y pues es que no me gusta ir ahí donde está el pasillo, porque pues no sé, los hombres pues están altos y te pegan aquí [señalando el hombro] pues el pene, y yo, no me gusta, es intolerable para mí, entonces siempre prefiero irme de lado de la ventana... En esa ocasión iba sola, en donde sólo hay un lugar, y ya iba así muy cerca de mí, y yo sentí, no sé, yo creo que es mucho repudio o asco... fue para mí muy ofensivo, porque ellos yo creo que están muy conscientes de lo que hacen. (Participante Grupo 2: 30-39 años). 

ciudad como espacio plural, vol. 6, núm. 1, pp. 57-76. En: http://www.ucm.es/info/angulo/volumen/Volumen06-1/articulos04.htm. ISSN: 1989-4015
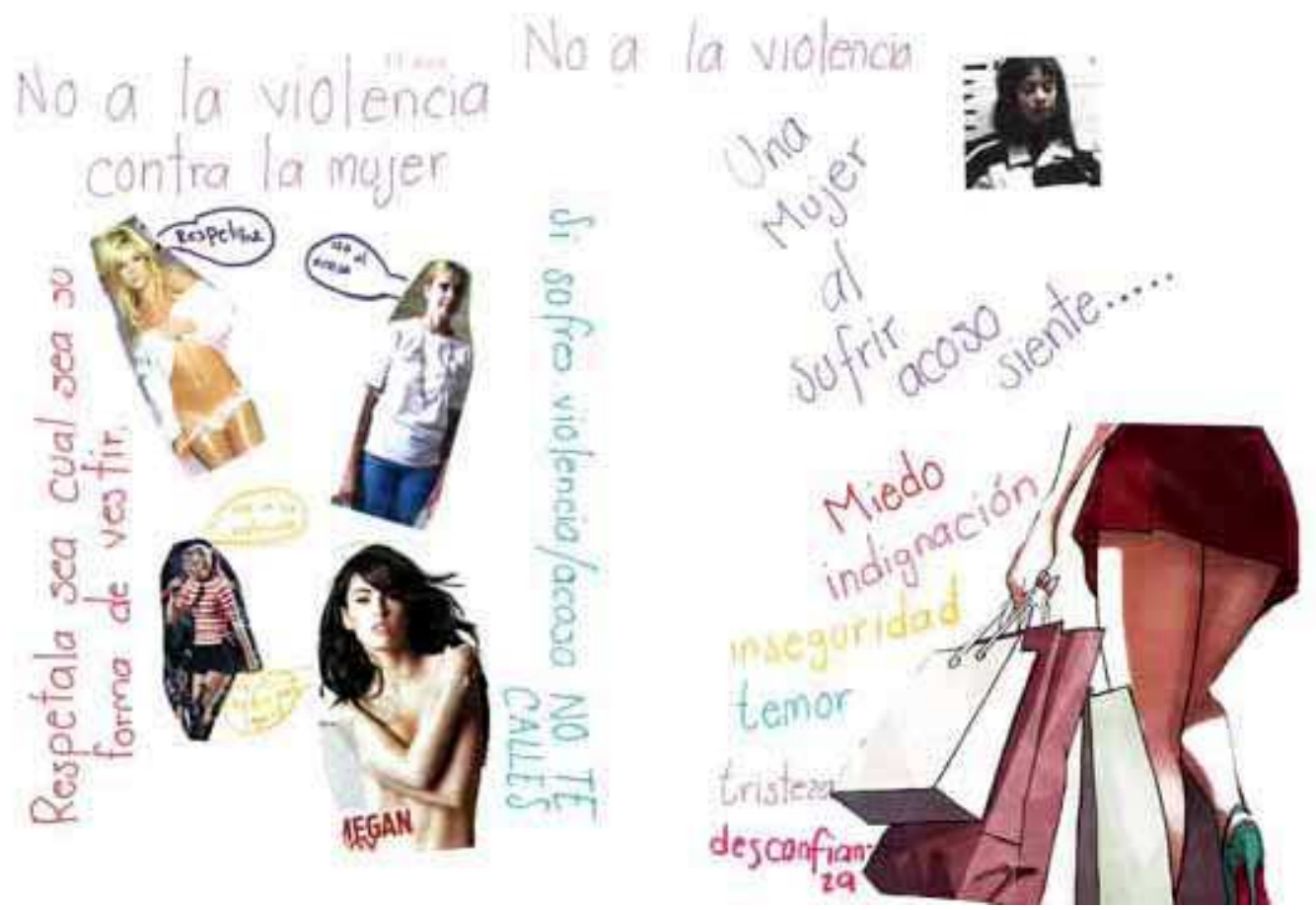

Figura 3. Gabriela, 19 años, soltera, sin hijos, estudiante.

\subsection{Ciudad de paso. Memorias, afectos y resonancias del acoso sexual}

Los relatos urbanos de acoso sexual tienen como soporte narrativo los desplazamientos y recorridos -a pie o en transporte públicocotidianos de las mujeres, que oscilan entre el adentro y el afuera, es decir, marcan dos pautas espaciales: entrar y salir de casa. Si bien estos trayectos se encuentran organizados principalmente en función del grupo etario al que pertenecen y de la actividad que realizan las mujeres (estudio, empleo, actividades de recreación y ocio, cuidado y crianza de los hijos o una combinación de éstas), sus narraciones comparten una imagen de la ciudad recreada desde el desplazamiento, es decir, desde las prácticas de movilidad que implican trasladarse de un lugar a otro, que empiezan y terminan en la casa como referente espacial.

Siguiendo el trazo de esta espacialidad, la calle es para las mujeres un lugar de paso, donde el viaje metropolitano ${ }^{8}$ es la

${ }^{8}$ García, Castellanos y Rosas (2013), distinguen entre el viaje urbano y el viaje metropolitano. De acuerdo con estos autores, el primero radica en realizar viajes dentro de la propia ciudad, y el segundo, incluye la ciudad y sus conurbaciones, es decir la Zona Metropolitana del Valle de México, la cual origina viajes largos entre el lugar de residencia y el destino o los destinos cotidianos. Este requiere de una combinación de medios de transporte para desplazarnos. De esta forma, habitar y transitar una de las ciudades más grandes del mundo suscita diversos problemas, fenómenos sociales, interacciones y experiencias diversas entre sus habitantes. 
FLORES PÉREZ, Edith (2014): "Narrativas urbanas de acoso sexual. Memorias, afectos y significaciones de las mujeres en la Ciudad de México" [en línea]. En: Ángulo Recto. Revista de estudios sobre la ciudad como espacio plural, vol. 6, núm. 1, pp. 57-76. En: http://www.ucm.es/info/angulo/volumen/Volumen06-1/articulos04.htm. ISSN: 1989-4015 http://dx.doi.org/10.5209/rev_ANRE.2014.v6.n1.45323

principal actividad que realizan en el espacio urbano. Como se ha dicho, la experiencia urbana de la movilidad es fundamental en la construcción de los significados y las imágenes subjetivas de la ciudad, en un sentido físico y simbólico, anclado en la experiencia del cuerpo: se camina aprisa, se padece el tráfico, se duerme en el trayecto. Los afectos, discursos y representaciones que aluden a las prácticas cotidianas urbanas se enmarcan en los traslados, es principalmente durante éstos donde las mujeres han sido objeto de alguna forma de violencia sexual.

Participante: A mí lo que me pasó fue que en esta ruta, yo iba a la universidad en la mañana, como a las 6:30 y a esa hora ya están muy llenos los camiones, entonces me tocó subirme por atrás, [...] y un señor me estaba arrimando su miembro en mi pierna, entonces yo puse mi morral de este lado, y [...] a mí sí me da mucho coraje, a mí la verdad me da mucha pena porque decirle al tipo éste y que me diga otra cosa, prefiero evitar que siga diciendo. (Participante Grupo 1: 18-29 años)

A mí una vez se me acercó el hombre y me acercó su miembro, yo me sentí... Iba en el trolebús... yo me sentí súper indefensa... no sabía qué hacer, sentía que me estaban violentando, me sentí como... ¿qué onda, no? Me sentí atacada, mucho, fue muy feo, me sentí indefensa y aparte no sabía qué hacer, no sabía cómo reaccionar ante eso que había pasado... (Participante Grupo 2: 18-29 años)

Un aspecto central de los hallazgos aquí presentados, es la forma en que las mujeres recrean tales escenas a través de un relato emocional que articula la experiencia en términos de la intensidad del riesgo o del nivel de incomodidad y peligro percibido. Los relatos evocan así un cúmulo de emociones referentes no sólo al miedo de las mujeres a la violencia sexual, sino que configuran la escena del acoso y la experiencia espacial posterior a ella, a pesar incluso de que transcurre en un lapso de corta duración. Narrar el acoso sexual implica una trama emocional que comienza con la conciencia de sí mismas, del otro y de las circunstancias que enmarcan la escena. Identificamos una secuencia de tensiones subjetivas en la producción del relato construidas a partir de algunos de los siguientes registros de la experiencia corporal o una combinación de éstos: shock o desconcierto por la agresión, miedo a que continúe o aumente, sentimientos de impotencia e indefensión, enojo y frustración, asco del contacto físico -del olor, el aliento o fluido corporal del extraño-, vergüenza por la agresión o por aparecer ante los otros como objetos de la escena. La tristeza, inseguridad, desagrado, culpa, miedo, sentido de desconcierto y de injusticia ante la situación, son ecos del acoso que se extienden a otras escenas y a otros momentos. 
Participante: No, pues ihorrible! yo nada más quería llegar a mi... yo quería olvidarme de ese lugar, me bloqueé, la única, como el único punto a dónde llegar, era a mi casa, porque me sentía invadida, me sentía agredida, o sea, todo, tenía mucho asco, llegué a mi casa, y directito lo que llegué a hacer fue a vomitar... [...] No, no, no, ya no, para nada no... y además la zona también, ese, pues sí el metro, el [autobús], tenía yo que buscar alternativas para sentirme despejada, para sentirme, no sentirme acosada o igual iba en el [autobús], o así, pero, yo tenía que tener identificadas las salidas, o sea, yo no me podía sentar en medio, yo tenía que ir a fuerza cerca de las puertas porque en medio empezaba a sentirme... mucha ansiedad o a la mejor si ahora me subo al metro tengo que ir en la puerta, yo no me puedo ir en medio del vagón. (Participante Grupo 1: 30-39 años)

Los relatos comparten una trama de emociones construidas social y culturalmente, desde las reacciones que aparecen de manera súbita frente a la violencia hasta las resonancias que transcienden la escena del acoso: fijando marcas de peligro en los espacios y delimitando las temporalidades, desplazándose como un límite que se encarna en la movilidad de las mujeres, en la organización de sus itinerarios, en las formas de viajar, de habitar la ciudad y de ser habitadas por ella.

Participante: A partir de eso tú te sientes insegura o amenazada de alguna manera, el simple hecho de subirte, yo por ejemplo sí soy mucho de que me subo al transporte, ya sea camión, metro o lo que sea, y yo sí observo como qué personas vienen a mi alrededor, ya será que es una manera como de viajar... (Grupo 2: 18-29 años)

La memoria de los cuerpos femeninos se actualiza cada vez que las mujeres recorren el espacio urbano. Las resonancias del acoso sexual producen así mapas de la ciudad delimitados física y simbólicamente, teniendo un correlato en la experiencia corporal y subjetiva: apresurar el paso, andar con inseguridad, sentir desconfianza ante cualquier extraño, salir o dejar de hacerlo a determinadas horas y lugares o a condición de ir acompañadas, modificar el vestido, la ruta, sentir un límite en la libertad para caminar. 


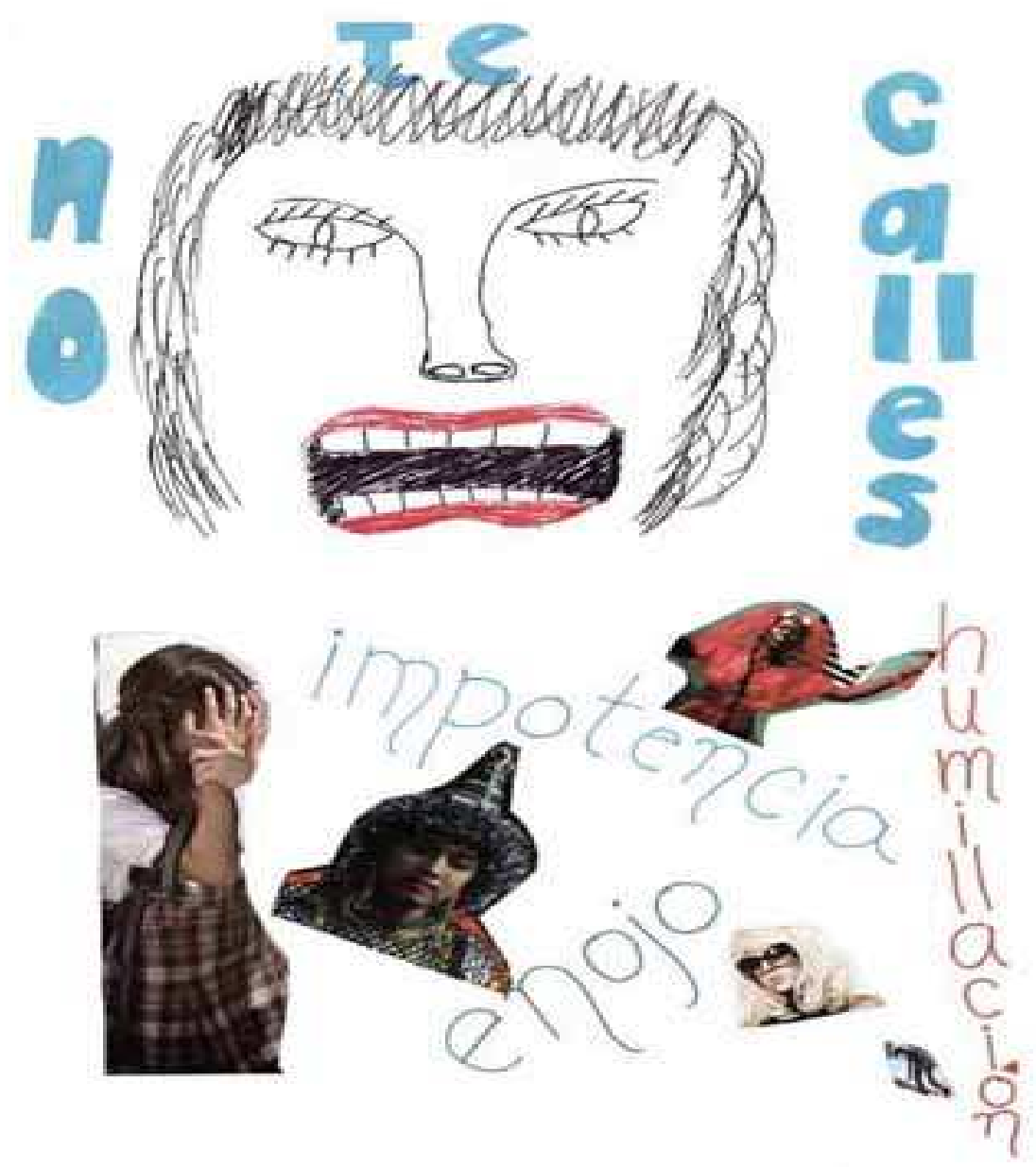

Figura 4. Nora, 24 años, soltera, sin hijos, estudiante.

\subsection{Andar la ciudad. Procesos de agencia y creatividad femenina}

Como hemos visto, un tema que recorre el corpus de narrativas analizadas es el acoso sexual como parte de las múltiples dimensiones que configuran la experiencia femenina de la ciudad. No obstante la configuración de las violencias sexuales como experiencias cotidianas y socialmente compartidas, no significa que sean vividas con resignación y pasividad. Contrario a una visión estereotipada y esencialista que coloca a las mujeres como víctimas, sus relatos se construyen a partir de una voz propia que repudia los actos de violencia, que considera que es inaceptable y que se opone a su normalización e invisibilización.

Uno de los hilos temáticos que entretejen los relatos desde una visión potencialmente transformadora es la narración de las violencias sexuales desde un sentido de coerción de su libertad, de limitación espacial y temporal del espacio urbano para las mujeres. Esto revela una forma de narrar la ciudad narrándose a sí mismas desde el reconocimiento de la restricción espacial como efecto de la discriminación de género. En este reconocimiento reside un acto de 
FLORES PÉREZ, Edith (2014): "Narrativas urbanas de acoso sexual. Memorias, afectos y significaciones de las mujeres en la Ciudad de México" [en línea]. En: Ángulo Recto. Revista de estudios sobre la ciudad como espacio plural, vol. 6, núm. 1, pp. 57-76. En: http://www.ucm.es/info/angulo/volumen/Volumen06-1/articulos04.htm. ISSN: 1989-4015 http://dx.doi.org/10.5209/rev_ANRE.2014.v6.n1.45323

cuestionamiento y denuncia del sistema de género que organiza las relaciones sociales expresadas en el uso y apropiación diferencial y jerárquico del espacio urbano.

Yo creo que es una situación generalizada, las dificultades que tiene una mujer al moverse sola por la ciudad, o sea de, no es solo la colonia en la que uno viva, vivo en una colonia muy segura, en donde hay luz eléctrica, pero si me dan las 12:30 de la noche, me da terror caminar aunque esté a dos cuadras, pido un taxi, porque dos cuadras se vuelven un terreno inhóspito, al ser una mujer sola, y tiene que ver con una cultura en donde estar sola es sinónimo de vulnerabilidad, entonces, como baja [...] la velocidad un automovilista, baja la velocidad una patrulla, es como si inmediatamente los hombres se sintieran con el derecho de atemorizar a las mujeres, en ese sentido creo que mas allá de la zona donde uno se mueva, yo lo siento generalizado, o sea, ese es el temor que a mí me da, esa es la única parte que realmente me limita en esta ciudad, sentir que no tengo la confianza de moverme sola a la hora que yo quiera, porque, inmediatamente corro un riesgo, y pues, creo que eso pasa en todos lados. (Participante 30-39 años)

Al tiempo que los relatos aluden al imaginario del miedo a la violencia sexual, éstos se materializan en las prácticas espaciales de las mujeres. En este sentido, aunque encontramos algunas diferencias por grupo etario, sobre todo vinculadas con las actividades que realizan las mujeres y su temporalidad, todas coinciden en que el acoso sexual afecta su vida cotidiana, su tranquilidad y la manera de andar la ciudad. No obstante, y a pesar del miedo a sufrir un acto de violencia sexual, las mujeres transitan del temor individual a la indignación social y a la creación de una serie de estrategias para andar la ciudad y lidiar, protegerse, evitar, cuestionar y denunciar el acoso sexual configurándose como agentes activos de su vida.

Si bien las mujeres señalan que cuanto más joven se es, se tiende a contar con menos recursos personales para enfrentar el acoso sexual, con la edad y la experiencia han aprendido a sentirse más seguras y a tener mayor control sobre la situación. Esto no quiere decir que dejen de sentir miedo o que hayan dejado de ser sorprendidas por escenas de acoso sexual; a pesar de ello, las mujeres no se asumen como víctimas y despliegan estrategias para enfrentar el acoso en sus viajes cotidianos a través de recursos personales anclados en las posturas del cuerpo y en el uso del espacio, y a través también de recursos sociales e institucionales: algunas enfrentan de manera directa al sujeto acosador, otras lo evidencian, lo confrontan, lo increpan o bien, lo denuncian. Lejos de organizar sus relatos en los marcos convencionales de género, aunque con distintos matices y gradaciones, las mujeres señalan que 
un cambio social debe recaer no sólo en los individuos, sino en las familias, las instituciones y la publicidad, principalmente.

Los relatos de las mujeres cuestionan los estereotipos de género y ponen en tela de juicio creencias sociales tales como un supuesto instinto sexual masculino irrefrenable que actúa sobre la pasividad femenina. De este modo, sus relatos elaboran posiciones críticas con la discriminación basada en el género y con las visiones estereotipadas. Por ejemplo, cuestionan las normas que les fueron inculcadas desde niñas, como elegir el vestido para evitar el acoso y asumir la responsabilidad de la agresión.

Entonces yo voy a las escuela en Tláhuac, está por el Reclusorio Oriente, entonces mi papá siempre: "No, es que cómo te vas así, en el camión, que andas provocando a la gente, que no sé qué", mi papá me lo dice y mi mamá me dice, "No pero al rato que amanezcas muerta en Xochiaca ni te quejes", así un buen de cosas... Con el novio que yo tenía igual, era igual, es que a mí no me gusta que te vistas así, no pues no me gusta, porque a mí no me gusta que otro tipo te ande viendo, y aparte provocas a que te falten al respeto, pero ¿Por qué? Si es una manera libre de vestirme. (Participante Grupo 2: 1829 años)

Asimismo, las mujeres más jóvenes señalan la importancia que tienen los medios de comunicación, la función de las instituciones sociales y la cultura en la construcción de una ciudad segura y respetuosa de los derechos de sus ciudadanas y ciudadanos. Sus relatos se entretejen a partir de un discurso de derechos y de ejercicio de su ciudadanía; en contraste, las mujeres adultas mayores adjudican la responsabilidad del cambio social a la familia, donde asumen un papel protagónico como educadoras, y al mismo tiempo, cuestionan a la luz de una visión retrospectiva una serie de creencias, normas y valores convencionales con los que fueron educadas. Las distintas posturas conllevan sus propias implicaciones; por ahora, lo que resaltamos aquí son los procesos de agencia y creatividad femenina para cuestionar y revertir los efectos del sistema de género que ha colocado históricamente a las mujeres en una condición de invisibilidad que genera vulnerabilidad social mas no victimización, la cual se resisten a aceptar y a reproducir, transformando un destino de subordinación en una oportunidad de cambio. 


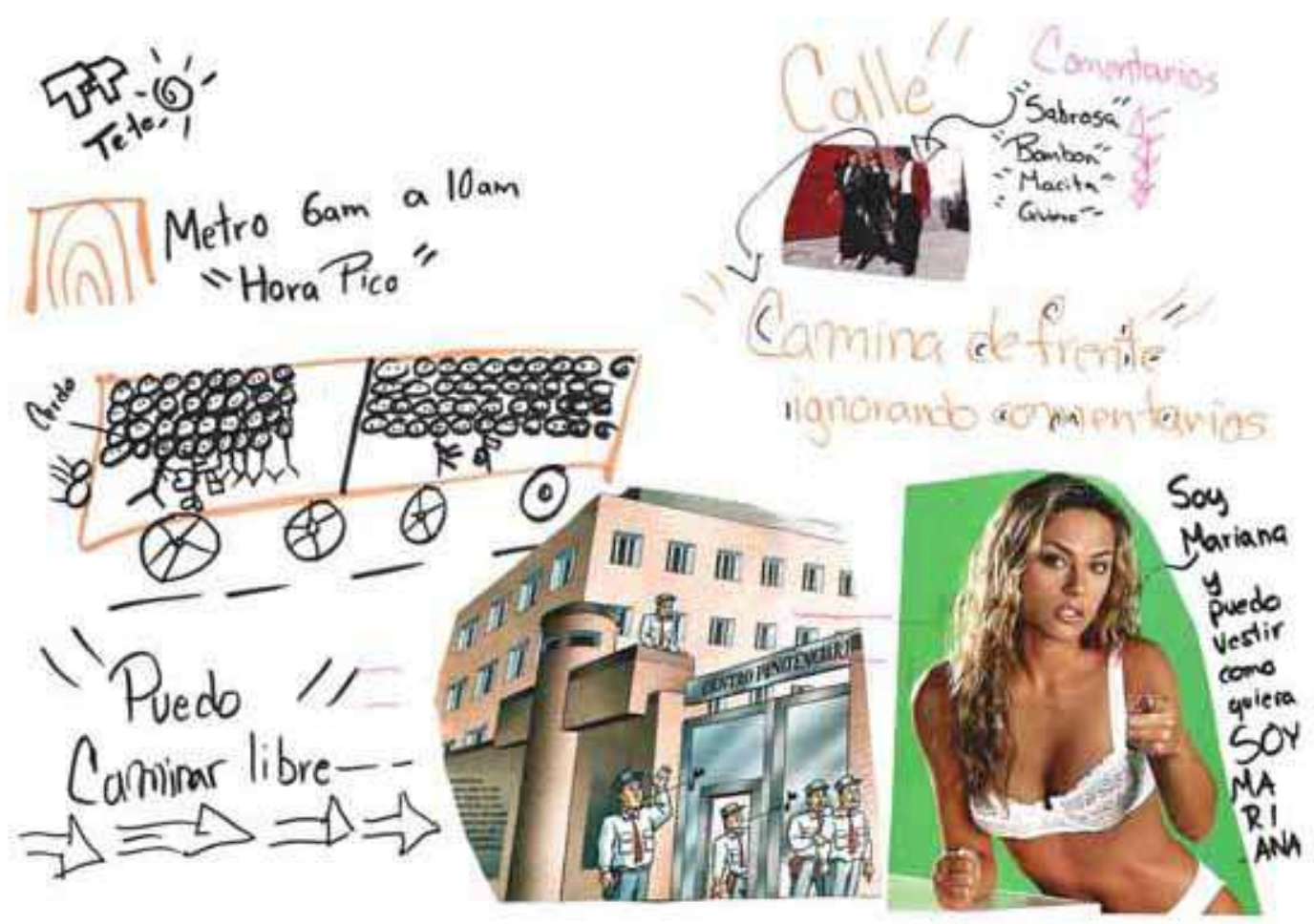

Figura 5. Tamara, 30 años, soltera, sin hijos, profesionista.

\section{Coda}

Al inicio de este trabajo señalamos la importancia de pensar la ciudad desde una postura en la investigación que parte del reconocimiento de las mujeres como sujetos históricamente situados y utilizando el género como categoría de análisis social para el estudio de la vida de las mujeres en la ciudad y del acoso sexual como núcleo del análisis, en tanto emerge de las narrativas urbanas como una de las principales temáticas que caracterizan las prácticas espaciales cotidianas de este colectivo.

Con base en una lectura feminista de la relación entre mujeres y ciudad, esta perspectiva permite contrarrestar el desconocimiento de la magnitud, los procesos y las implicaciones de la violencia de género vivida por las mujeres y visibilizar la tolerancia social que encubre el problema. Con esta visión, presentamos un acercamiento a la vivencia de las mujeres para conocer el acoso sexual a partir de las memorias, los afectos y significaciones que configuran la experiencia espacial individual y colectiva, más allá de la materialidad del espacio y dando énfasis a la perspectiva del sujeto que lo habita: explorando la forma en que las mujeres relatan la interpretación de sus vivencias y construyen un imaginario social urbano a través de su espacialidad.

El relato de la experiencia constituye así un recurso valioso para la elaboración y la resignificación del miedo a la violencia, una asociación subjetiva difícil de discernir en la experiencia de las 
FLORES PÉREZ, Edith (2014): "Narrativas urbanas de acoso sexual. Memorias, afectos y significaciones de las mujeres en la Ciudad de México" [en línea]. En: Ángulo Recto. Revista de estudios sobre la ciudad como espacio plural, vol. 6, núm. 1, pp. 57-76. En: http://www.ucm.es/info/angulo/volumen/Volumen06-1/articulos04.htm. ISSN: 1989-4015 http://dx.doi.org/10.5209/rev_ANRE.2014.v6.n1.45323

mujeres. La posibilidad de narrar las violencias sexuales experimentadas tiene un valor potencial para significar el vacío de representación que la violencia imprime como acontecimiento por efímera y fugaz que sea su duración y utilice mecanismos "sutiles" en su operación. Las violencias sexuales imprimen una sensación de daño en las mujeres que el relato permite elaborar desafiando el olvido y los mecanismos de invisibilización y silenciamiento que sostienen y reproducen la violencia de género. El relato recupera así las memorias de lo efímero y disruptivo del acoso, como un medio de conquistar la propia voz y de hacer visible la agencia y capacidad de las mujeres con la que han enfrentado este problema en su vida cotidiana.

De acuerdo con el enfoque que hemos dado a este trabajo, el análisis de la violencia de género en las coordenadas de la vida urbana debe partir del contexto social en el que se inscribe, en este caso en particular, del reconocimiento de los cambios que se han dado en materia de legislación para proteger y promover la seguridad de las mujeres en la ciudad, los cuales, consideramos deben pensarse a la luz de la complejidad del problema y partiendo de un conocimiento profundo de las dinámicas de la violencia de género y del modo en que afecta de manera específica a las mujeres. En este sentido, el artículo intenta aportar una comprensión de la violencia sexual basada en el conocimiento de la vivencia de las mujeres, la cual depende de las circunstancias y características particulares de la escena urbana de acoso sexual. El enfoque subraya así la importancia de ampliar la mirada sobre la violencia de género a partir de la interpretación de las mujeres sobre sus propias experiencias y con ello, documentar y reconocer las diversas formas en que las mujeres viven el acoso en el espacio urbano en tanto experiencias cotidianas que contribuyen a comprender el problema y, sin embargo, han sido subvaloradas o se trivializan.

Al explorar la relación entre el miedo de las mujeres a la violencia sexual y su percepción y uso del espacio urbano, encontramos una serie de repercusiones en su participación en la vida social que van desde evitar salir hasta modificar sus pautas de movilidad, su vestido e incluso la percepción de su propio cuerpo. Esto demuestra que la vida de las mujeres en la ciudad está signada por un uso diferencial y jerárquico del espacio urbano a través de diversas formas de control social como es el acoso sexual y otras formas de violencia tan sutiles o directas, que atentan contra la autonomía de las mujeres y el ejercicio pleno de su ciudadanía.

En razón de ello, en este trabajo sostenemos que las formas de violencia, por más intangibles y volátiles que parezcan, socavan la libertad, la integridad física y emocional de las mujeres, reproduciendo la subordinación histórica a la que han estado sometidas. Por tanto, consideramos que la violencia sexual en el 
FLORES PÉREZ, Edith (2014): "Narrativas urbanas de acoso sexual. Memorias, afectos y significaciones de las mujeres en la Ciudad de México" [en línea]. En: Ángulo Recto. Revista de estudios sobre la ciudad como espacio plural, vol. 6, núm. 1, pp. 57-76. En: http://www.ucm.es/info/angulo/volumen/Volumen06-1/articulos04.htm. ISSN: 1989-4015 http://dx.doi.org/10.5209/rev_ANRE.2014.v6.n1.45323

espacio urbano requiere de un ejercicio analítico para elucidar los procesos sociales y subjetivos que la sostienen, la reproducen y la toleran. De ahí la necesidad de comprender cabalmente lo que experimentan las mujeres y las implicaciones de esta forma de violencia en el uso y la experiencia de la ciudad.

\section{Bibliografía}

AGUILAR, Miguel Ángel (2009): "Narrativa y vida urbana", en Miguel Ángel Aguilar; Eduardo Nivón; Ana María Portal, y Rosalía Winocur (coords.), Pensar lo contemporáneo: De la cultura situada a la convergencia tecnológica, pp. 155-165. Barcelona: Anthropos / Universidad Autónoma Metropolitana, Iztapalapa.

AGUILAR, Miguel Ángel (2013): "Ciudad de interacciones: el cuerpo y sus narrativas en el metro de la Ciudad de México", en Miguel Angel Aguilar y Paula Soto (coords.), Cuerpos, espacios y emociones. Aproximaciones desde las ciencias sociales. México: Universidad Autónoma Metropolitana, Iztapalapa.

BOURDIEU, Pierre (2000): La dominación masculina. Barcelona: Anagrama. DEL VALLE, Teresa (1997): Andamios para una nueva ciudad. Madrid: Cátedra.

FLORES, Edith (2013): "Escrito en la banqueta: Archivo de Memoria Visual. Escenas de acoso sexual en la ciudad de México" [en línea]. Bifurcaciones. Revista de Estudios Culturales Urbanos, vol. 15, Verano 2013, Diciembre-Febrero. En: http://www.bifurcaciones.cl/2013/12/escrito-en-la-banqueta-archivode-memoria-visual/

GARCÍA, Néstor; CASTELLANOS, Alejandro; y ROSAS, Ana (2013): La ciudad de los viajeros. Travesías e imaginarios urbanos: México, 1940-2000. México: Fondo de Cultura Económica / Universidad Autónoma Metropolitana, Iztapalapa.

GAYTÁN, Patricia (2009): Del piropo al desencanto. Un estudio sociológico. México: Universidad Autónoma Metropolitana, Unidad Azcapotzalco.

LINDÓN, Alicia (2008): "De las geografías constructivistas a las narrativas de vida espaciales como metodologías geográficas cualitativas". Revista da ANPEGE, vol. 4, pp. 7-26.

SABATÉ, Ana; RODRÍGUEZ, Juana María; y DÍAZ, María Ángeles (2010): Mujeres, espacio y sociedad. Hacia una geografía del género. Madrid: Síntesis.

SCRIBANO, Adrián (2008): El proceso de investigación social cualitativo. Buenos Aires: Prometeo Libros.

SOTO, Paula (2011): "La ciudad pensada, la ciudad vivida, la ciudad imaginada. Reflexiones teóricas y empíricas". La Ventana, núm. 34, pp. 7-38. 